\author{
Review Article \\ www.ijrap.net (ISSN:2229-3566)
}

\title{
A CRITICAL REVIEW OF JWARAHARA YOGAS OF AYURVEDIC CLASSICS: A PARADIGM TO REVERSE PHARMACOLOGY
}

Hareendran Nair J ${ }^{1}$, Sajna SA ${ }^{2}$, Monisha M ${ }^{2}$, Sandhu G. Joseph ${ }^{3}$, Vijaya R ${ }^{3}$, Aiswarya P ${ }^{4}$, Shan Sasidharan ${ }^{1 *}$

${ }^{1}$ Pankajakasthuri Herbal Research Foundation, Pankajakasthuri Ayurveda Medical College campus, Killy, Thiruvananthapuram, Kerala, India

${ }^{2}$ Department of Rasa Shastra and Bhaishajya Kalpana, Pankajakasthuri Ayurveda Medical College and P.G. Centre, Killy, Thiruvananthapuram, Kerala, India

${ }^{3}$ Department of Dravya guna Vijnanam, Pankajakasthuri Ayurveda Medical College and P.G. Centre, Killy, Thiruvananthapuram, Kerala, India

${ }^{4}$ Department of Shalakya Tantra, Pankajakasthuri Ayurveda Medical College and P.G. Centre, Killy, Thiruvananthapuram, Kerala, India

Received on: 19/12/20 Accepted on: 29/01/21

*Corresponding author

E-mail: drshansasidharan@yahoo.co.in

DOI: $10.7897 / 2277-4343.120120$

\begin{abstract}
Jwara is the first and foremost among all somatic diseases. Although an independent disease, it is also seen manifested in the form of premonitory symptom, symptom and causative factor of various disorders. 2019-20 has witnessed a new pandemic identified as Corona virus (COVID-19) with adverse health issues. In proportion to the wide variety of diseases, viral vaccines are very few, that too with adverse effects. Hence there is an urgent need of most promising Indigenous drugs with antipyretic and anti-viral activity in the current scenario. A critical analysis is made to explore the Jwarahara Yogas of classics to unfold the Antiviral, Antipyretic, Antioxidant and Immunomodulatory potential of phytochemicals in formulations. An attempt has been made to explore the antiviral and antipyretic potential of Amrutotharam Kashayam, one of the most popular and widely used Jwarahara yoga in classics. The review will definitely give new insights on the synergistic actions of phytochemicals in formulations to revalidate the clinical evidences and will throw lime light on repurposing of the documented novel drugs and combinations in classics to offer unique preventive strategies and therapeutic solutions to the present pandemic and emerging viral infections.
\end{abstract}

Keywords: Jwara, Jwarahara Yogas, Antipyretic, Antiviral, Phytochemicals, Formulation.

\section{INTRODUCTION}

Ayurveda has a different and unique outlook on treatment modality of multifactorial disease entities with varied symptoms. The novel concept of samyoga/combination of herbs and their multi targeted mode of action is evident in the compendiums of Ayurveda. The phytochemicals from plants have been broadly studied for their antipyretic and antiviral activity. But the mechanisms by which poly herbal drugs and their extracts act differ in many respects from the actions of single substances or synthetic drugs ${ }^{1}$. In fact, Jwarahara Yogas of classics are designed in a unique way that the anti-inflammatory, anti-viral, antipyretic, antioxidant, immunomodulatory potentials of drugs act in synergy to enhance the body's overall natural resistance to the disease-causing agent rather than directly neutralizing the agent itself. Validation of Ayurvedic drugs with reverse pharmacology is the need of the hour.

Jwara is a disease entity which simultaneously afflicts the body, mind and sense organs ${ }^{2}$. Jwara is classified into various types based on Doshik predominance, caused by internal or external factors in the classical text books of Ayurveda. Indulgence in improper diet and regimen vitiates the tridoshas which in turn hampers agni, obstructs the channels of rasa and sweda and expels agni (Digestive and Metabolic factors) from its site to different parts of the body resulting in elevation of body temperature ${ }^{3}$. Nidana Parivarjana (eliminating the root cause) is the first line of treatment in any disease. While explaining the treatment of Jwara,
Acharyas clearly explain to avoid factors which aggravate Doshas, specifically Pitta Dosha.

A thorough analysis of classics reveals that the fundamental principle of combating any form of Jwara is digesting the ama, preserving the agni, relieving Shrotorodha (Obstructive pathology occurring in channels) and inducing sweat which inturn brings down the temperature.

The commonly used potent Kashayas (decoctions) \& Gutikas (tablets) mentioned under Jwara chikitsa are compiled (Table $1 \&$ 2) and analyzed by identifying the exact phytochemicals responsible for the definite pharmacological action of the drugs to revalidate the rationale of adopting these formulations in Jwara chikitsa. 10 Jwarahara Kashaya Yogas and 10 Gutika Yogas of poly herbal and herbo-mineral combination with remarkable therapeutic efficacy is enlisted from among the wide yet diverse group of formulations.

\section{Probable Mode of Action}

In Ayurveda, the mechanism of action of drug can be explained in terms of Rasa Panchaka viz; Rasa (taste), Guna (property), Virya (potency), Vipaka (Biotransformation of Rasa) and Prabhava (Exceptional action). On analyzing the formulations, it was observed that each formulation is unique in its own way due to its Rasa Panchaka and Dosha karma (action on vitiated doshas) capable enough to break the Samprapti (pathogenesis) of Jwara. 
Table 1: List of Kashaya Yogas with Phytochemicals and its Action

\begin{tabular}{|c|c|c|c|}
\hline \multirow[t]{2}{*}{ Ingredients } & \multicolumn{2}{|c|}{ Phytochemicals } & \multirow[t]{2}{*}{ Specific pharmacological actions } \\
\hline & Antipyretic & Antiviral & \\
\hline \multicolumn{4}{|c|}{ 1. Amrutotharam Kashaya (Sahasrayogam- Jwara prakarana) } \\
\hline $\begin{array}{l}\text { Heart leaved Moonseed } \\
\text { (Tinospora cordifolia) }\end{array}$ & $\begin{array}{c}\text { Flavonoid, } \\
\text { Diterpenoid, Alkaloid, } \\
\text { Berberin }\end{array}$ & Tinosporin $^{4}$ & Anti-pyretic \\
\hline $\begin{array}{c}\text { Ink nut } \\
\text { (Terminalia chebula) }\end{array}$ & Flavonoids $^{6}$ & $\begin{array}{l}\text { Chebulagic acid }^{5} \\
\text { Gallic acid } \\
\text { Galloy glucoses } \\
\text { Chebulinic acid }\end{array}$ & Antiviral activity \\
\hline \multirow{5}{*}{$\begin{array}{c}\text { Dry ginger } \\
\text { (Zingiber officinale) }\end{array}$} & \multirow[t]{5}{*}{ Gingerol } & Quercetin $^{7}$ & Anti-viral activity \\
\hline & & B-Sesquiphellandrene ${ }^{8}$ & Anti-rhino-viral activity \\
\hline & & Allicin $^{9}$ & Anti-influenza \\
\hline & & Ingenol $^{10}$ & Anti-viral activity \\
\hline & & 6-shogoals ${ }^{10}$ & Anti-viral activity \\
\hline \multicolumn{4}{|c|}{ 2. $\quad$ Shadanga paneeya - Jwara Chikitsa - A.H.Chi.1/15 } \\
\hline \multirow[t]{3}{*}{$\begin{array}{c}\text { Nut grass } \\
\text { (Cyperus rotundus) }\end{array}$} & Quercetin $^{11}$ & Quercetin & $\begin{array}{c}\text { Anti-pyretic activity, Anti-DENV-2 } \\
\text { Inhibitory activities, Influenza infection }^{13}\end{array}$ \\
\hline & Sequesturpenoids & Sequesturpenoids & Anti-HBV activity \\
\hline & $\beta$-Sitosterol & & Antipyretic activity $^{14}$ \\
\hline \multirow{2}{*}{$\begin{array}{c}\text { Sandalwood } \\
\text { (Santalum album) }\end{array}$} & \multirow[t]{2}{*}{-} & $\beta$-santalols ${ }^{15}$ & Anti-influenza $\mathrm{A} / \mathrm{HK}(\mathrm{H} 3 \mathrm{~N} 2)$ virus activity \\
\hline & & $\alpha$ - santalols ${ }^{15}$ & \\
\hline $\begin{array}{c}\text { Cuscus grass } \\
\text { (Vetiveria zizanioides) }\end{array}$ & - & - & Antipyretic activity \\
\hline \multirow[t]{2}{*}{$\begin{array}{c}\text { Indian fumitory } \\
\text { (Fumaria parviflora) }\end{array}$} & - & $\begin{array}{c}\text { Narlumicine* } \\
\text { Oxysanguinarine* } \\
\beta \text {-Sitosterol }\end{array}$ & Fumaria indica -DENV (Dengue Virus) inhibitor ${ }^{16}$ \\
\hline & & Quercetin $^{17}$ & \\
\hline \multicolumn{4}{|c|}{ Dry ginger* } \\
\hline \multicolumn{4}{|c|}{ Coleus** } \\
\hline \multicolumn{4}{|c|}{ Pachana Kashaya AH.Chi.1/65-66 } \\
\hline $\begin{array}{l}\text { Canchorie root plant } \\
\text { (Tragia involucrata) }\end{array}$ & $\begin{array}{c}\text { Tritrepenoid, } \\
\text { Flavonoids, Tannins }\end{array}$ & - & Anti-pyretic activity ${ }^{18}$ \\
\hline $\begin{array}{c}\text { Velvet leaf } \\
(\text { Cyclea peltata })\end{array}$ & 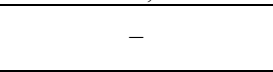 & $\begin{array}{c}\text { Bebeerine*19 } \\
\text { (Cissampelos pareira })\end{array}$ & $\begin{array}{c}\text { Protection against DENV (Dengue Virus) } \\
\text { infection*, Antipyretic activity }^{20}\end{array}$ \\
\hline \multicolumn{4}{|c|}{ Nut grass*/Fine leaf fumitory*/Dry ginger*/Cuscus grass*/Coleus* } \\
\hline \multicolumn{4}{|c|}{ 4. $\quad$ Pachana Kashaya (b) AH.Chi.1/65-66 } \\
\hline $\begin{array}{c}\text { Green chiretta } \\
\text { (Andrographis paniculata) }\end{array}$ & - & $\begin{array}{c}\text { Andrographolide } \\
\text { neoandrographolide } \\
\text { 14-deoxy-11,12- } \\
\text { didehydroandrographolide }\end{array}$ & $\begin{array}{c}\text { Viricidal activity }^{21} \text { against herpes simplex virus } 1 \\
\text { (HSV-1) } \\
\text { Antipyretic activity }\end{array}$ \\
\hline \multicolumn{4}{|c|}{ Heart leaved Moonseed*/Nut grass*/Dry ginger* } \\
\hline \multicolumn{4}{|c|}{ 5. $\quad$ Guduchyadi gana Kashaya Ashtanga Hridaya sutra 15/16 } \\
\hline $\begin{array}{c}\text { Neem } \\
\text { (Azadirachta indica) }\end{array}$ & Nimbidin & $\begin{array}{l}\text { Flavonoids, Triterpenoids } \\
\text { Glycosides, } \\
\text { Beta-pinene limonene }\end{array}$ & $\begin{array}{l}\text { Antipyretic action }{ }^{23} \text { - In hyper pyretic rabbits } \\
\text { Antiviral action }{ }^{24} \text { - action coxsackie B }\end{array}$ \\
\hline $\begin{array}{c}\text { Coriander } \\
\text { (Coriandrum sativum) }\end{array}$ & - & Beta-pinene\& limonene ${ }^{25}$ & $\begin{array}{l}\text { Antiviral activity against herpes simplex virus type } \\
1 \text { (HSV-1) in vitro }\end{array}$ \\
\hline $\begin{array}{c}\text { Red sandalwood } \\
\text { (Pterocarpus santalinus) }\end{array}$ & Flavonoids & - & Antipyretic activity ${ }^{26}$ \\
\hline \multicolumn{4}{|c|}{ Orris root */ Heart leaved Moonseed * } \\
\hline \multicolumn{4}{|c|}{ Wild Himalayan cherry (Prunus cerasoides)- Antioxidant** } \\
\hline \multicolumn{4}{|c|}{ 6. Nimbadi kashaya Chakradutta, Jwara chikitsa :101 } \\
\hline $\begin{array}{l}\text { Indian night shade } \\
\text { (Solanum ptychanthum) }\end{array}$ & $\begin{array}{l}\text { Flavonoids, Steroid } \\
\text { Saponins, } \\
\text { Anthraquinone, } \\
\text { Tannins }\end{array}$ & $\begin{array}{l}\text { Flavonoids Terpenoids } \\
\text { lignans Sulphides } \\
\text { Polyphenolics } \\
\text { Coumarins }\end{array}$ & $\begin{array}{l}\text { Antipyretic activity }{ }^{27} \\
\text { Antiviral effects by inhibiting the formation of viral } \\
\text { DNA or RNA }\end{array}$ \\
\hline \multicolumn{4}{|c|}{ Long pepper - Pippali */ Neem */ Dry ginger*/ Heart leaved Moonseed */ Deodar */ King of bitters* } \\
\hline \multicolumn{4}{|c|}{ Piper chaba/ Spiked ginger lily (Hedychium spicatum) - Antioxidant** } \\
\hline \multirow{3}{*}{$\begin{array}{c}\text { Grapes } \\
\text { (Vitis vinifera) }\end{array}$} & 7. & Drakshadi kashaya A.H. & $55-58$ \\
\hline & - & Resveratrol (RV) ${ }^{28}$ & $\begin{array}{l}\text { Inhibit the in vitro and In vivo replication of } \\
\text { influenza virus. In vivo anti-Herpes simplex virus } \\
\text { activity, antiviral action against polyomavirus } \\
\text { inhibition of varicella-zoster virus replication in } \\
\text { vitro human immunodeficiency virus type } 1 \text { (HIV) }\end{array}$ \\
\hline & $\begin{array}{l}\text { Quercetin, Rutin, } \\
\text { Kaempferol, Luteolin } \\
\text { Phenolic acids } \\
\end{array}$ & - & Antipyretic \\
\hline $\begin{array}{l}\text { Indian butter tree } \\
\text { (Madhuca indica) }\end{array}$ & Flavonoid, Quercetin & - & Antipyretic ${ }^{29}$ \\
\hline
\end{tabular}


Hareendran Nair J et al / Int. J. Res. Ayurveda Pharm. 12 (1), 2021

\begin{tabular}{|c|c|c|c|}
\hline \multirow[t]{2}{*}{$\begin{array}{c}\text { Liquorice } \\
\text { (Glycyrrhiza glabra) }\end{array}$} & - & Glycyrrhizin $^{30}$ & $\begin{array}{l}\text { Varicella-zoster virus (VZV) in vitro } \\
\text { RNA and DNA viruses, } \\
\text { human immunodeficiency virus (HIV) infection. } \\
\text { SARS (severe acute respiratory syndrome) virus, } \\
\text { i.e., FFM-1 and FFM-2 }\end{array}$ \\
\hline & - & $\begin{array}{l}\text { Glycyrrhizin, Licorice and } \\
\text { Glycyrrhizic acid }\end{array}$ & $\begin{array}{l}\text { In vitro antiviral activity on Japanese encephalitis } \\
\quad \text { virus against SARS-Coronavirus }{ }^{31}\end{array}$ \\
\hline $\begin{array}{c}\text { Lodh tree, } \\
\text { (Symplocos racemosa) }\end{array}$ & $\begin{array}{l}\text { Phenolic Glycoside }{ }^{32} \\
\text { Alkaloids, Steroids }\end{array}$ & 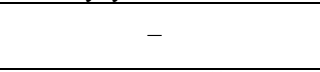 & Antipyretic activity \\
\hline $\begin{array}{l}\text { Indian sarsaparilla } \\
\text { (Hemidesmus indicus) }\end{array}$ & - & $\beta$-sitosterol ${ }^{33}$ & Antipyretic activity \\
\hline \multirow{3}{*}{$\begin{array}{l}\text { Indian gooseberry } \\
\text { (Phyllanthus emblica) }\end{array}$} & \multirow{3}{*}{ - } & Ascorbic acid & HIV infection ${ }^{34}$ \\
\hline & & $\begin{array}{l}\text { Gallic acid, Ellagic acid, } \\
\text { Tannins and Catechins }\end{array}$ & Anti-HIV-1 activity, $\mathrm{HSV}^{34}$ \\
\hline & & $\begin{array}{c}1246 \mathrm{TGG}^{35} \\
(1,2,4,6-\mathrm{Tetra}-\mathrm{O}-\text { galloyl- } \\
\text { beta-D-glucose })\end{array}$ & Anti-HSV activity \\
\hline $\begin{array}{c}\text { Indian lotus } \\
\text { (Nelumbo nucifera) }\end{array}$ & $\begin{array}{c}\text { Flavonoids, } \\
\text { Glycosides, } \\
\text { Kaempferol } \\
\text { derivatives } \\
\text { Nelumboroside A and } \\
\text { B 2. Isorhamnetin } \\
\text { glycosides 3-O- } \beta \text {-D- } \\
\text { glucopyranoside, } \\
\text { Isorhamnetin 3-O-a-L- } \\
\text { Rhamnopyranosyl- } \\
(1 \rightarrow 6)-\beta-D- \\
\text { glucopyranoside } \\
\end{array}$ & $\begin{array}{l}(+)-1(\mathrm{R})-\text { coclaurine, }(-)- \\
\text { 1(S)- Norcoclaurine and } \\
\text { Quercetin }\end{array}$ & $\begin{array}{l}\text { Antipyretic activity }{ }^{36} \\
\text { Anti-HIV activity }{ }^{37}\end{array}$ \\
\hline $\begin{array}{c}\text { Blue lotus } \\
(\text { Nelumbo nucifera })\end{array}$ & Nymphayol ${ }^{38}$ & - & Antipyretic \\
\hline $\begin{array}{l}\text { Ceylondate palm } \\
\text { (Grewia asiatica) }\end{array}$ & - & - & $\begin{array}{c}\text { Antipyretic activity } \\
\text { Antiviral } \\
\text { An }\end{array}$ \\
\hline \multicolumn{4}{|c|}{ Sandalwood*/Nutgrass*/Coleus*/Gmelina*/Lotus*/Wild Himalayan cherry*/Cuscus grass* } \\
\hline \multicolumn{4}{|c|}{$\begin{array}{l}\text { 8. Panchatikta Kashaya } \\
\end{array}$} \\
\hline $\begin{array}{c}\text { Febrifuge plant } \\
\text { (Solanum xanthocarpum) }\end{array}$ & - & Flavonoids $^{40}$ & Anti-Viral activity \\
\hline \multicolumn{4}{|c|}{$\begin{array}{c}\text { Dry ginger (Zingiber officinale) } * / \text { Heart leaved Moonseed (Tinospora cordifolia) } * / \text { Green chiretta (Andrographis paniculata) } * / \text { Orris root } \\
\text { (Inula racemosa) - Antioxidant }\end{array}$} \\
\hline \multicolumn{4}{|c|}{$\begin{array}{ll}9 . \quad \text { Indukantam kashaya (Sahasrayogam) } \\
\end{array}$} \\
\hline $\begin{array}{c}\text { Stone apple } \\
\text { (Aegle marmelos) }\end{array}$ & Skimmianine $^{41}$ & Marmelide $^{41}$ & $\begin{array}{l}\text { Anti-viral property against Herpes Simplex Type 1, } \\
\text { Inhibition on HIV-1 entry and HIV-protease }\end{array}$ \\
\hline \multirow[t]{2}{*}{$\begin{array}{c}\text { Indian Elm } \\
\text { (Caesalpinia crista) }\end{array}$} & \multirow[t]{2}{*}{-} & Betulinic acid ${ }^{42}$ & $\begin{array}{l}\text { Anti-viral property against Herpes Simplex Type 1, } \\
\text { Inhibition on HIV-1 entry and HIV-protease }\end{array}$ \\
\hline & & Betulin $^{43}$ & Anti-viral \\
\hline $\begin{array}{l}\text { Indian trumpet flower } \\
\text { (Oroxylum indicum })\end{array}$ & Flavonoids $^{44}$ & 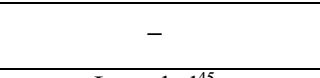 & Anti-Pyretic \\
\hline $\begin{array}{l}\text { Rose flower fragrant } \\
\text { (Stereospermum } \\
\text { suaveolens) }\end{array}$ & 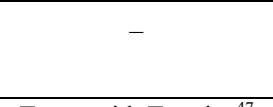 & $\begin{array}{l}\text { Lapachol }^{45} \\
\text { Apigenin }^{46}\end{array}$ & Anti-Viral \\
\hline Dabra (Uraria picta) & Terpenoid, Tannins $^{47}$ & Flavonoids $^{48}$ & Anti-Pyretic, Anti-Viral activity \\
\hline \multicolumn{4}{|c|}{$\begin{array}{c}\text { Indian nightshade (Solanum anguivi) } * / \text { Febrifuge plant (Solanum xanthocarpum) */Long pepper (Piper longum) */ } \\
\text { Dry ginger (Zingiber officinale) } *\end{array}$} \\
\hline \multicolumn{4}{|c|}{$\begin{array}{l}\text { Devil's weed (Tribulus terrestris) (Antioxidant)/Long pepper (Piper longum) (immuno- modulatory) /Balinese long pepper } \\
\text { (Piper retrofractum) (Antioxidant)/Ceylon leadwort (Plumbago zeylanica) (Antioxidant)/Deodar (Cedrus deodara) (Antioxidant)/ } \\
\text { Arni (Clerodendrum phlomidis) (antioxidant)/Headache tree (Gmelina arborea) (immuno-modulatory)/Tick tree (Desmodium gangeticum) } \\
\text { (Antioxidant) } * *\end{array}$} \\
\hline \multicolumn{4}{|c|}{ 10. Patoladi Kashaya A.H.Chi.1/65-66 } \\
\hline \multirow{2}{*}{$\begin{array}{l}\text { Bitter snake gourd } \\
\text { (Trichosanthes } \\
\text { cucumerina) }\end{array}$} & \multirow[t]{2}{*}{-} & $\begin{array}{l}\text { Triterpenoid alcohol } \\
\text { Euphol }^{49}\end{array}$ & Anti-Viral \\
\hline & & Coumarin $^{50}$ & Viral growth Inhibition \\
\hline \multirow{2}{*}{$\begin{array}{c}\text { Indian gooseberry } \\
\text { (Phyllanthus emblica) }\end{array}$} & Flavonoids $^{51}$ & & Anti-Pyretic, Prostaglandin synthesis inhibitor \\
\hline & - & Pentagalloylglucose $\mathrm{s}^{52}$ & Inhibit influenza \\
\hline $\begin{array}{l}\text { Hellebore (Picrorhiza } \\
\text { kurroa) }\end{array}$ & - & $\begin{array}{l}\text { Aungmaygaoside D (4), } \\
\text { Sylvestroside IV dimethyl } \\
\text { acetal (7), Sweroside }(8)^{53}\end{array}$ & Viral protein $\mathrm{R}$ inhibitors \\
\hline \multicolumn{4}{|c|}{$\begin{array}{l}\text { Ink nut (Terminalia chebula) } * / \text { Dry ginger (Zingiber officinale) } * / \text { Orris root }(\text { Inula racemosa }) * / \text { Heart leaved Moonseed } \\
(\text { Tinospora cordifolia }) * / \text { Febrifuge plant (Solanum xanthocarpum) } * / \text { Neem }(\text { Azadirachta indica }) *\end{array}$} \\
\hline & Beleric myrob & an (Terminalia bellerica) $(\mathrm{Ar}$ & oxidant) $* *$ \\
\hline
\end{tabular}


Table 2: List of Tablets with its phytochemicals and its action

\begin{tabular}{|c|c|c|c|}
\hline \multirow[t]{2}{*}{ Ingredients } & \multicolumn{2}{|c|}{ Phytochemicals } & \multirow[t]{2}{*}{ Specific pharmacological actions } \\
\hline & Antipyretic & Antiviral & \\
\hline \multicolumn{4}{|c|}{ 1. Tribhuvanakeerti rasa (Yoga Ratnakara) } \\
\hline $\begin{array}{c}\text { Aconite } \\
\text { (Aconitum ferox) }\end{array}$ & - & $\begin{array}{c}\text { Hypaconitine } \\
\text { Songorine, } \\
\text { Mesaconitine } \\
\text { Aconitine }^{54} \\
\end{array}$ & $\begin{array}{l}\text { Alkaloids against tobacco mosaic virus (TMV) and } \\
\text { cucumber mosaic virus (CMV). }\end{array}$ \\
\hline \multirow{2}{*}{$\begin{array}{l}\text { Black pepper } \\
\text { (Piper nigrum) }\end{array}$} & \multirow{2}{*}{$\begin{array}{l}\text { Alkaloid Piperine } \\
\text { (trans isomer of } 1- \\
\text { piperoyl piperidine } \\
\end{array}$} & \multirow[t]{2}{*}{ Piperamides $^{56}$} & Antipyretic activity-yeast induced pyrexia in mice. \\
\hline & & & $\begin{array}{l}\text { Antiviral activity - inhibit coxsackie virus type B3 } \\
\text { (CVB3). }\end{array}$ \\
\hline $\begin{array}{l}\text { Liquid media used for } \\
\text { trituration: Juicy extract of } \\
\text { leaves of Holy basil } \\
\text { (Ocimum tenuiflorum) }\end{array}$ & - & Terpenoid $^{57}$ & $\begin{array}{l}\text { Antipyretic activity- Tested in typhoid-paratyphoid } \\
\text { A/B vaccine-induced pyrexia in rats. }\end{array}$ \\
\hline $\begin{array}{l}\text { Extract of leaves of White } \\
\text { thorn apple (Datura metal) }\end{array}$ & & Atropine $^{58}$ & $\begin{array}{c}\text { Antiviral activity against herpes simplex virus, } \\
\text { influenza virus }\end{array}$ \\
\hline \multicolumn{4}{|c|}{ Purified cinnabar*/ purified borax*/ long pepper*/ extract of Ginger rhizome * } \\
\hline \multicolumn{4}{|c|}{ 2. Mrityuinjaya rasa (Bhaishajya Ratnavali Jwara Rogadhikara) } \\
\hline & & & Antiviral activity- against $\mathrm{H} 9 \mathrm{~N} 2$ virus $^{59}$ \\
\hline $\begin{array}{c}\text { Darada / Cinnabar } \\
\text { HgS } \\
\end{array}$ & - & - & Antiviral activity ${ }^{60}$ \\
\hline $\begin{array}{c}\text { Tankana /Borax } \\
\mathrm{Na}_{2} \mathrm{~B}_{4} \mathrm{O}_{7} .10 \mathrm{H}_{2} \mathrm{O}\end{array}$ & - & - & Antidote activity profile against Aconite $^{61}$ \\
\hline \multicolumn{4}{|c|}{ Vatsanabha*/Maricha*/Kana* } \\
\hline \multicolumn{4}{|c|}{ 3. $\quad$ Anandabhairava rasa (Rasendra sara sangraha-Jwaradhikara) } \\
\hline Nut meg (Myristica fragrans) & - & $\begin{array}{l}\text { Terpenoids like } \\
\text { sabinene, Myristicin } \\
\text { and Eugenol }^{62}\end{array}$ & In vitro anti-rotavirus activity \\
\hline Lemon juice (Citrus lemon) & - & $\begin{array}{c}\text { Hesperidin and } \\
\text { Vitamin } C^{63}\end{array}$ & $\begin{array}{c}\text { Counteract the cell infection by SARS-CoV-2 } \\
\text {-reduce viral pathogenicity of NDV Newcastle } \\
\text { Disease Virus } \\
\end{array}$ \\
\hline \multicolumn{4}{|c|}{$\begin{array}{c}\text { Hingula /cinnabar*/Tankana/Borax*/Monkshood* Aconitum ferox /Long pepper* } \\
\text { Piper longum /Black pepper * Piper nigrum / Dry ginger* }\end{array}$} \\
\hline \multicolumn{4}{|c|}{ 4. Hinguleswara rasa (Bhaishajya Ratnavali Jwara Adhikara) } \\
\hline \multicolumn{4}{|c|}{ Long pepper*/Cinnabar*/Monkshood* } \\
\hline \multicolumn{4}{|c|}{ 5. Rasa Manikya (Siddha bhaishajya manimala-jwara prakarana) } \\
\hline Arsenic tri- sulphide & $\mathrm{AS}_{2} \mathrm{~S}_{3}$ & & \\
\hline \multicolumn{4}{|c|}{ 6. Bilwadi gulika Ashtanga Hridaya Uttara 36/84-85 } \\
\hline \multirow[t]{2}{*}{$\begin{array}{l}\text { Pongan oil tree } \\
\text { (Pongamia pinnata) }\end{array}$} & \multirow[t]{2}{*}{$\begin{array}{l}\text { Glycosides, Sterols } \\
\text { Tannins }\end{array}$} & \multirow[t]{2}{*}{$\begin{array}{l}\text { Adenine Arabinoside, } \\
\text { Cytosine Idoxyuridine }\end{array}$} & $\begin{array}{c}\begin{array}{c}\text { Antipyretic activity in Brewer's yeast-induced } \\
\text { pyrexia in rats. }\end{array} \\
\end{array}$ \\
\hline & & & Antiviral against $\mathrm{HSV}-1$ and $\mathrm{HSV}-2^{65}$ \\
\hline $\begin{array}{l}\text { Stinking cassia } \\
(\text { Senna tora })\end{array}$ & - & $\begin{array}{c}\text { Flavonoids } \\
\text { Emodinanthraquinone }\end{array}$ & Antiviral- anti-SARS-CoV activity ${ }^{66}$ \\
\hline Turmeric (Curcuma longa) & - & $\begin{array}{l}\text { Curcumin, Gallium- } \\
\text { curcumin, } \mathrm{Cu}- \\
\text { curcumin }\end{array}$ & Reduction of HSV-1 replication, anti-HIV ${ }^{67}$ \\
\hline \multirow{2}{*}{$\begin{array}{l}\text { Indian berry (Berberis aristata) } \\
\text { Liquid media trituration: } \\
\text { goat's urine }\end{array}$} & \multirow{2}{*}{$\begin{array}{l}\text { Alkaloids, Tannins, } \\
\text { Terpenes, Resins, } \\
\text { Phenols }\end{array}$} & \multirow[t]{2}{*}{ Berberine $^{68}$} & Antipyretic \\
\hline & & & Antiviral \\
\hline \multicolumn{4}{|c|}{ Stone apple*/ Sacred basil*/ Deodar*/ Ink nut*/ myrobalan*/ Indian gooseberry *, / Long pepper*/ pepper*/ dry ginger* } \\
\hline \multicolumn{4}{|c|}{ Beleric** } \\
\hline \multicolumn{4}{|c|}{ 7. Sudarshana choorna/Gutika Bhaishajya Ratnavali Jwaradhikara 308-317 } \\
\hline $\begin{array}{c}\text { Sweet flag } \\
\text { (Acorus calamus) }\end{array}$ & 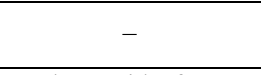 & $\begin{array}{c}\beta \text {-asarone } \\
\text { flavonoid } \\
\end{array}$ & Antiviral action- $\mathrm{HSV}-1$ and HSV-2. ${ }^{69}$ \\
\hline $\begin{array}{l}\text { Persian manna plant } \\
\text { (Alhagi maurorum) }\end{array}$ & $\begin{array}{c}\text { Flavonoids, fatty } \\
\text { acids, coumarins, } \\
\text { glycosides, sterols, } \\
\text { steroids. } \\
\end{array}$ & - & Antipyretic $^{00}$ \\
\hline \multirow{3}{*}{$\begin{array}{c}\text { Licorice } \\
\text { (Glycyrrhiza glabra) }\end{array}$} & & Glycyrrhizic acid & Antiviral activity- EV71, coxsackievirus A16 \\
\hline & & Glycyrrhizin & Antiviral- hepatitis C \\
\hline & & Licorice, Triterpene & Antiviral \\
\hline $\begin{array}{c}\text { Drumstick } \\
\text { (Moringa oleifera) }\end{array}$ & $\begin{array}{c}\text { phenolics, } \\
\text { flavonoids, tannins, } \\
\text { saponins, terpenoids, } \\
\text { isoquercetin } \\
\text { glycosides such as } \\
\text { niazirin, 4- } \\
\text { hydroxymellein, } \beta \text { - } \\
\text { sitosterol, and } \\
\text { vanillin. } \\
\end{array}$ & $\begin{array}{c}\text { Flavonoid } \\
\text { Tannin } \\
\text { Saponin }\end{array}$ & $\begin{array}{l}\text { Antipyretic }^{71} \\
\text { Antiviral }\end{array}$ \\
\hline $\begin{array}{c}\text { Asparagus } \\
\text { (Asparagus racemosus) }\end{array}$ & $\begin{array}{c}\text { Flavonoids } \\
\text { Saponins } \\
\end{array}$ & - & Antipyretic activity ${ }^{72}$ \\
\hline
\end{tabular}




\begin{tabular}{|c|c|c|c|}
\hline $\begin{array}{c}\text { Cinnamom bark } \\
\text { (Cinnamomum verum) }\end{array}$ & - & - & $\begin{array}{l}\text { Antiviral activity against Influenza virus } \\
\text { Parainfluenza and HSV } 1 \text { virus invitro.H1N1 }\end{array}$ \\
\hline Potash Alum & - & - & $\begin{array}{c}\text { As adjuvant in F1-RSV vaccines increases viral } \\
\text { clearance and Immunogenicity }{ }^{74}\end{array}$ \\
\hline \multicolumn{4}{|c|}{$\begin{array}{l}\text { False calumba*/ turmeric*//deodar*/ nut grass*/ Ink nut*/ Chinese pistache*/ febrifuge plant*/ dry ginger*/ Fine leaf fumitary*/ Neem* } \\
\text { Long pepper* / Coleus */ spiked ginger lilly*/ Orris root*/ root of long pepper */ False calumba*/ Turmeric*/ tree turmeric*/ } \\
\text { Red sandalwood*/ wild Himalayan cherry*/ khaskhas grass*/ Ticktree* (Desmodium gangeticum)/ Ajwan* (Trachyspermum ammi)/ } \\
\text { Atis* (Aconitum heterophyllum)/ stone apple*/ pepper*/ gooseberry*/ Heart leaved moonseed*/ Ceylon leadwort*/ Ballon vine* } \\
\text { (Swertia chirata) / Dabra* (Uraria picta)/ Bitter snake gourd* (Trichosanthes dioica) }\end{array}$} \\
\hline \multicolumn{4}{|c|}{$\begin{array}{l}\text { Indian gentian (Gentiana kurroo)/Musk mellow (Abel moschus moschatus) / Stink vine (Paederia foetida) / } 3 \text { leaved pine } \\
\text { (Pinus roxburghii)/ Frangipani vine / Conessi seeds (Holarrhena antidysentrica) (Chonemorpha fragrans) }\end{array}$} \\
\hline \multicolumn{4}{|c|}{ 8. Vasantamalati rasa (Siddha bhaishajya manimala- Jwara prakarana) } \\
\hline \multirow[t]{2}{*}{ Gold bhasma (Gold-Au) } & $\begin{array}{l}11 \% \text { and } 20 \% \text { of } \\
\mathrm{Au}^{75}\end{array}$ & - & Anti-pyretic \\
\hline & - & $\begin{array}{l}\text { Average size of } 56-57 \\
\mathrm{~nm} \mathrm{Au}\end{array}$ & Inhibit Influenza virus \\
\hline \multicolumn{4}{|c|}{ Purified cinnabar*/ Pepper* } \\
\hline \multicolumn{4}{|c|}{ Pearl bhasma $\left(\mathrm{CaCO}_{3}\right)$ / Calamine/zinc ore $(\mathrm{ZnO})$ / Butter / lemon juice (Citrus lemon) } \\
\hline \multicolumn{4}{|c|}{$\begin{array}{ll} & \text { Vettumaran gulika (Sahasrayogam) } \\
\end{array}$} \\
\hline \multirow{3}{*}{$\begin{array}{c}\text { Celery } \\
\text { (Apium graveolens) }\end{array}$} & \multirow{3}{*}{$\begin{array}{l}\text { Flavonoids } \\
\text { Alkaloids }^{77}\end{array}$} & Thymol $^{78}$ & Anti-influenza, Anti-viral \\
\hline & & p-cymene ${ }^{79}$ & Anti-viral, Herpes simplex virus Type 1 \\
\hline & & $\gamma$-terpinene -t9 $^{79}$ & Anti-Viral \\
\hline Blue vitriol & & $\mathrm{CuSO}_{4}$ & Anti-Viral $^{80}$ \\
\hline Realgar & & $\mathrm{As}_{2} \mathrm{~S}_{2}$ & Anti-viral, Anti-HSV-2 activity $^{81}$ \\
\hline \multicolumn{4}{|c|}{ Cinnabar*/ Borax*/ Black pepper*/Indian aconite*/ Ginger juice* } \\
\hline \multicolumn{4}{|c|}{ 10. Chukkum tippalyadi gutika (Sahasrayoga Gutika prakarana -2) } \\
\hline $\begin{array}{l}\text { Indian aloe } \\
(\text { Aloe vera })\end{array}$ & $\begin{array}{c}\text { Salicylic acid }^{82} \\
\beta \text { sitosterols } \\
\text { Flavonoids }^{83} \\
\end{array}$ & r & Anti-Pyretic activity \\
\hline $\begin{array}{c}\text { Sweet flag } \\
(\text { Acorus calamus }) \\
\end{array}$ & - & b-Asarone ${ }^{84}$ & $\begin{array}{l}\text { Inhibit Herpes simplex virus HSV-1 and HSV-2 } \\
\text { replication }\end{array}$ \\
\hline $\begin{array}{c}\text { Ballon wine } \\
\text { (Cardiospermum halicacabum) }\end{array}$ & - & $\begin{array}{c}\text { Flavonoids } \\
\text { Phenolic acids }\end{array}$ & Anti-Viral \\
\hline Breast milk & & Mucin $^{86}$ & Anti-poxvirus activity, Anti-HIV \\
\hline \multicolumn{4}{|c|}{ Dry ginger*/ long pepper */ White cumin*/ Green chiretta* } \\
\hline \multicolumn{4}{|c|}{$\begin{array}{c}\text { Cumin seed (Cuminum cyminum) / Woodenbegar (Axis axis) / Indian copaltree (Veteria indica) / Camphor (Cinnamomum camphora) / } \\
\text { Civet cat secretion (Viverra zibetha) }\end{array}$} \\
\hline
\end{tabular}

Majority of the ingredients have tikta (bitter) as Pradhana rasa (primary taste) and Katu (pungent)/ kashaya (astringent) as anurasa (secondary taste). Among the Shadrasa's, tikta rasa possess Jwarahara property. It acts by virtue of its Deepana, Pachana and Lekhana property thereby ignites digestive fire, removes ama visha owing to its vishaghna nature (removes toxins), improves digestion, clear the rasavaha srotas (channels), improves taste, reduces daha (burning sensation), arochaka (anorexia) and subsequently alleviates pitta dosha \& subsides Jwara (fever). Tikta-kashaya rasa, laghu-ruksha guna and sita virya of the combination helps in pacifying Kapha and pitta. Katu Vipaka does Pachana of doshas especially Kapha along with Pitta and stabilizes dhatwagni. The formulations were found to have sita virya and ushna virya dugs in which ushna virya induces Swedana, Ama Pachana, Deepana and removes Shrotorodha whereas sita virya mitigates pitta dosha.

According to Modern Pharmacology, the probable mode of action may be ascribed to the major groups of common plant secondary metabolites (SM) that produce a definite physiological action. The synergistic effects of these secondary metabolites may inhibit microorganisms and may interfere with metabolic processes or may modulate gene expressions and signal transduction pathways ${ }^{87}$. An attempt made to understand the diversity of SM and their modes of action, either alone or in combinations may contribute to the recorded pharmacological activities.
On analyzing the Jwarahara Kashaya Yogas (Table 1); we could enlist 16 drugs which possessed phytochemicals with demonstrated antipyretic activity whereas 23 ingredients had phytochemicals with antiviral potential against a variety of viruses. A total of 12 ingredients were found to exhibit both actions. Majority of the ingredients had profound immunomodulatory profile. Exploring the mechanisms of the antipyretic (Jwaraghna) action of the herbs in the formulation in Ayurveda thus involves antiviral, immunomodulatory and antioxidant potential of drugs working in synergy which will give a totally different perspective on treatment modality for fevers.

\section{Analysis of Antipyretic activity}

The essential elements of the fever physiologic pathway are release of pyrogenic cytokines by inflammatory cells in response to some exogenous pyrogen (e.g. infection), induction of cyclooxygenase (COX) 2 activation of the arachidonic acid cascade, and enhanced biosynthesis of prostaglandin $\mathrm{E}_{2}\left(\mathrm{PGE}_{2}\right)$ by hypothalamic vascular endothelial cells ${ }^{88}$. Through its effect on thermoregulatory neurons located in the preoptic area of the anterior hypothalamus, $\mathrm{PGE}_{2}$ acts to raise the hypothalamic thermal set point and thereby induce peripheral and thermogenic mechanisms to increase core temperature. Antipyretic agents might interrupt the fever response at any step along this pathway. ${ }^{89}$ 
In majority of the drugs of the Yogas (Table $1 \& 2$ ) In vitro antipyretic activity effect in yeast provoked elevation of body temperature in rats comparable to that of paracetamol (standard drug) was established. Various researchers have claimed that the antipyretic effect of $\beta$-Sitosterol which is found in Musta (Cyperus rotundus) and Parpata (Fumaria parviflora) is comparable to that of aspirin. The antipyretic activity of various drugs may be attributed to the high content of flavonoids in drugs like Amrita (Tinospora cordifolia), Madhuka (Madhuca indica), Vacha (Acorus calamus), Rakta Chandana (Pterocarpus santalinus), Kamala (Nelumbo nucifera), Dunduka (Oroxylum indicum), Amalaki (Phyllanthus embelica), Draksha (Vitis vinifera), Haritaki (Terminalia chebula), Shatavari (Asparagus racemosus) etc. by inhibiting prostaglandin synthesis in hypothalamus. A study reported that Quercetin may inhibit fever causing inflammatory mediators ${ }^{90}$

In a recent study, the chemical analysis to ascertain the marker compounds of the Jwarahara Mahakashaya indicated the presence of flavonoids, which are well known for their antipyretic properties. $^{91}$

In a nutshell, the antipyretic action of drugs may be interpreted as follows. $\beta$-Sitosterol block the pathway of phospholipase and inhibit the production of arachidonic acid. Flavonoids and its related compounds block the action of Cyclooxygenase pathway and inhibit the production prostaglandins (PGE2) thus reducing the fever ${ }^{92}$.

\section{Analysis of Antiviral activity}

There are several mechanisms which govern the antiviral activity of phytochemicals. Few anti-viral phytochemicals, bind to carbohydrate moiety and tend to target the cell entry. These mechanisms will limit the viral attachment, penetration, coating, synthesis of proteins, assembly and release. Several in silico and in vitro studies have revealed the promising use of phytochemicals for the treatment of viral infections. A thorough analysis of Jwarahara property of drugs revealed astonishing antiviral potentials of phytochemicals (Table $1 \& 2$ ) and the mechanism of action of drugs can be illustrated in the following phases of viral life cycle.

\section{Inhibition of viral attachment}

6-Shogoals, 6-Gingerol, Allicin of Ginger blocks viral attachment and internalization. Tinosporin of Heart Leaved Moonseed inhibit the virus from establishing infection to target the $t$ helper cells ${ }^{93}$. Glycyrrhizin, of licorice root does not allow the virus cell binding ${ }^{94}$. Mucin in breast milk binds and traps virus particles thus acts as artificial shield ${ }^{86}$. A recent study proposed that the benefit of hesperidin from citrus fruits may derive both from the binding to the coronavirus spike and from its anti-inflammatory activity ${ }^{63}$. Joshi et al. identified hesperidin among several natural molecules that strongly bind to SARS-CoV-2 main protease, and interestingly also to the viral receptor angiotensin-converting enzyme 2 (ACE-2).

\section{Inhibition of virus entry}

Quercetin, in plants like Musta (Cyperus rotundus), Shunthi (Zingiber officinale), Parpata (Fumaria parviflora) etc and
Curcumin ${ }^{103}$ in Curcuma longa exhibits initial phase of antiviral activity by interaction with viral surface glycoprotein (HA, hemagglutinin) and inhibition of virus entry into the cell. ${ }^{95}$

\section{Inhibits uncoating or release of virus particles}

Glycirrhin inhibits the penetration, uncoating or release of virus particles ${ }^{96}$. Eugenol in Myristica fragrans does direct inactivation of Virus particles ${ }^{97}$

\section{Inhibition of RNA synthesis}

$\beta$-santalols in Sandalwood (Santalum album) decreases viral mRNA synthesis ${ }^{15}$. Curcumin in Curcuma longa inhibits viral RNA, protein synthesis and virus titer ${ }^{98}$.

\section{Inhibits glycosylation of viral proteins}

When the viral proteins are under-glycosylated there are chances of new virion formation but in the presence of Atropine the virions will remain non-infectious ${ }^{104}$. The Chemical Atropine which is present in Datura metel blocks the glycosylation of viral proteins. There will be reduction in production of infective viral particles. The Coumarin present in Bitter snake gourd (Trichosanthes curcumerina) inhibits viral growth ${ }^{50}$.

\section{Inhibition of Viral replication}

The chemicals in Neem such as flavonoids, triterpenoids, glycoside, Beta-pinene limonene interfere at an early event of virus replication cycle ${ }^{105}$. Chebulagic acid and chebulinic acid in Haritaki (T. chebula) inhibits virus replication. Glycyrrhizic acid could inhibit the replication of coronavirus SARS in vitro ${ }^{94}$. $\beta$ Asarone of Acorus calamus prevents the replication of both HSV1 and HSV-2 ${ }^{99}$. Thymol in celery ${ }^{100}$ and Eugenol may interact with viral envelope can cause damage to viral envelopes of freshly formed virions and can cause inhibition of viral replication at the initial stage ${ }^{101}$ Glycyrrhizin is effective in controlling viral replication of SARS (severe acute respiratory syndrome) virus ${ }^{102}$

In this review, a humble attempt is made to explore the diverse plant secondary metabolites and explain their underlying modes of action to revalidate the time-tested evidences of our sacred science. In this regard, an attempt is made to analyse the probable mode of action of Jwarahara formulations citing Amrutotharam Kashayam, the most popular and potent yoga for treating Jwara as an example.

\section{Probable Mode of Action of Amrutotharam Kashayam}

\section{Antipyretic activity (Figure 1)}

The flavonoids present in Tinospora cordifolia (Amrita) are known to target prostaglandins which are involved in Pyrexia. Inhibiting central production of $\mathrm{PGE}_{2}$ is a well-known mechanism of antipyretic agents but activated leukocytes and endothelial cells in peripheral areas of inflammation also represent potential drug target ${ }^{106}$. It appears that the flavonoids content of Terminalia chebula may be responsible for its antipyretic activity by inhibiting prostaglandin synthesis in hypothalamus ${ }^{107}$ (Figure 1). 


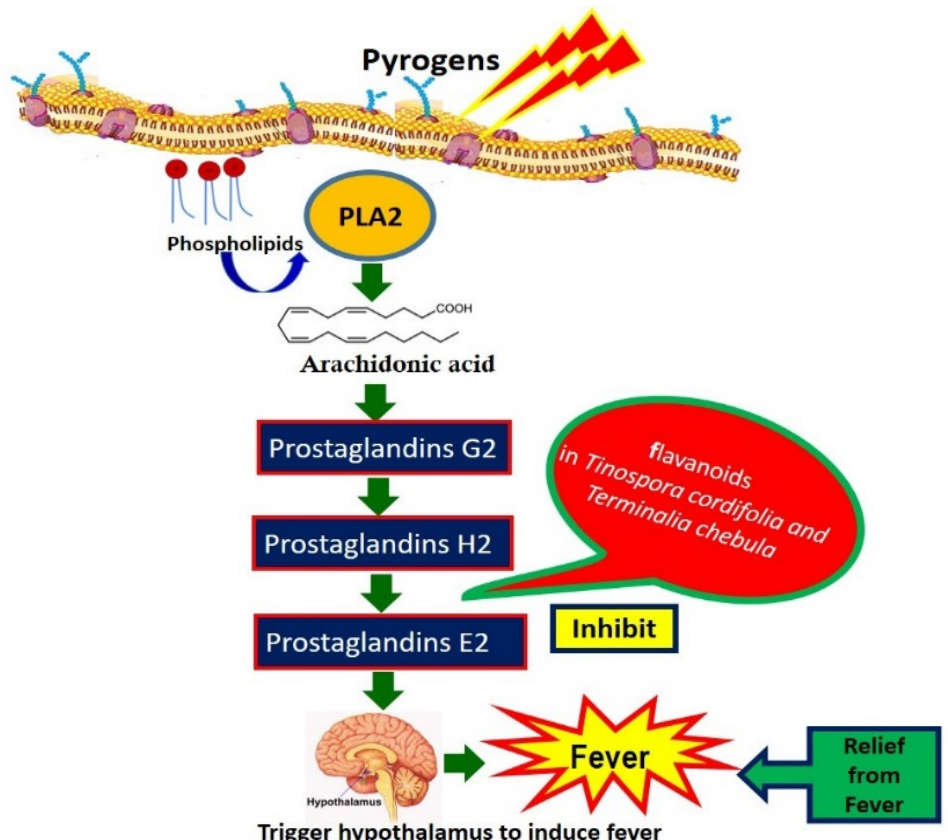

Figure 1: Probable Mechanism of Antipyretic Activity of Amrutotharam Kashayam

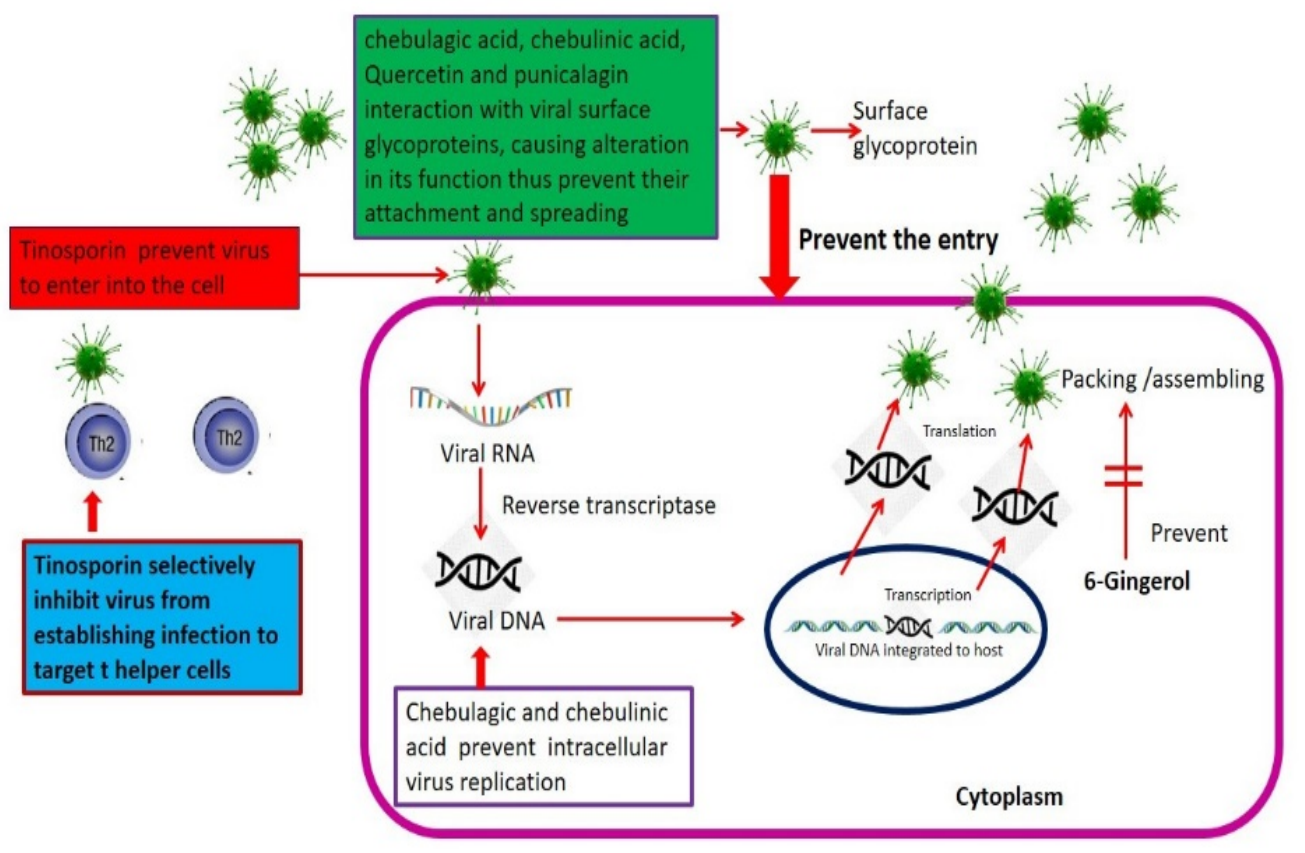

Figure 2: Probable Mechanism of Antiviral Activity of Amrutotharam Kashayam

\section{Antiviral activity (Figure 2)}

Flavonoids in Tinospora cordifolia ${ }^{108}$ possesses antiviral properties. Phosphorylation of protein by cytokines II is inhibited by flavonoids which help in the cell arrest of HIV at integration traction phage of virus. Tinosporin selectively inhibit virus from establishing infection to target $\mathrm{t}$ helper cells. The exact mechanism by which it prevents infection of virus and host cell is not known but on analyzing from cell culture incubated with virus doesn't show any series activation of host cell. It suggests either virus is not entering into the cell or, after entry it could not get activated. The antiviral activity of Chebulagic acid, a hydrolysable tannin in Terminalia chebula was exhibited in-vitro and in-vivo and significant recovery was found due to the inhibition of viral replication in different tissues of chebulagic acid treated mice.

T. Chebula extract, chebulagic acid and chebulinic acid, the hydrolysable tannins exhibit antiviral activity by interacting with viral surface glycoproteins ${ }^{109}$. This prevents the attachment and spread to the VERO cells and in fact prevents cell to cell spread. Chebulagic acid and Punicagilin isolated from the fruits of $T$. chebula blocks the interaction with host cell surface glycosaminoglycans and thus inhibited HSV -1 viral particles, viral binding and penetration to cell as well as secondary infection by targeting the glycoproteins involved in attachment and membrane fusion. Hence the extract of $T$. chebula may target Hepatitis C Viruses, HIV, dengue viruses that uses 
glycosaminoglycans as a door for host cell entry. Due to their large molecular weight, chebulagic acid and chebulinic acid is unlikely to penetrate to Vero cells and hence may not interfere in viral replication and hence it binds to viral surface glycoproteins and inhibits cell to cell spread.

6-gingerol of Zingiber officinale (Shunthi) shows highest binding affinity and interaction with multiple targets of COVID-19 including Viral proteases, RNA binding protein, Spike protein ${ }^{110}$.

Quercetin can target influenza viral particles instead of the host cell. Generally, Hemagglutinin (HA) is an essential major glycoprotein on the surface of the influenza virus responsible for entry and fusion of virions. Quercetin could interact with HA and subsequently interfere with virus entry. Quercetin may have a medium binding affinity to influenza HA protein. Quercetin may affect the bound molecules' dynamics and thus alter the binding event. Quercetin efficiently inhibits entry of the influenza A virus, which may be mainly ascribed to its interaction with the HA2 subunit, which mediates the low $\mathrm{pH}$-induced fusion of the viral envelope with the endosomal membrane. Quercetin may target viral surface HA protein and thus inhibit virus infection. Therefore, it can be inferred that quercetin may exert its antiviral activity via interaction with viral HA protein and then inhibit virus entry into the cell ${ }^{95}$.

\section{Immunomodulatory Action}

Tinosporin is an immunomodulatory agent. It increases the white cell count in pathological states to increase the phagocytes of the foreign material. This leads to the destruction of microbes in infections. T. cordifolia and its constituent $\alpha$-D-glucan stimulate NK cells, B cells, and T cells with simultaneous production of various immune-stimulatory cytokines [1] [2] i.e., A novel $(1,4)$ $\alpha$-D-glucan from $T$. cordifolia activates the immune system by activating macrophages via TLR6 signaling and NF- $\mathrm{KB}$ activation mechanism, leading to cytokine and chemokine production. Melatonin plays an important role as an immunomodulator, as well as performing other physiological functions. It has been reported to be an integral part of the immune system and exerts direct and/or indirect stimulatory effect on both cellular and humoral immunity ${ }^{111}$.

One study ${ }^{109}$ showed that treatment with $T$. chebula caused the expression of a thick band of protein, indicating increased production of melatonin. Hence, T. chebula extract exhibits immune-stimulant action by enhancing melatonin secretion in the pineal gland by exerting direct and/or indirect stimulatory effect on both cellular and humoral immunity; and proliferation of lymphocytes as indicated by the increase in the number of $\beta$ and $\mathrm{T}$ cells which release cytokines and growth factors that regulate other immune cells and secretion of antibodies in the blood.

In a study, an attempt to identify and analyse the chemical constituents in Amrutotharam Kashayam using modern chromatographic and spectroscopic techniques, revealed the presence of phenolics in abundance. Phenolic acids such as quinic acid, protocatechuic acid, gallic acid, and chebulic acid were identified in the formulation ${ }^{112}$. Even though the Mass spectrum chromatogram of the formulation could not validate the phytochemicals of all the constituents especially Amrita $(T$. cordifolia), similar significant researches in this direction can pave new insights in fingerprinting of the final compound to ensure the genuineness and quality of the final product and can bring about newer dimensions in reverse pharmacological approach and drug discovery.

\section{CONCLUSION}

Phytochemical screening of the documented formulations in the present study revealed their synergistic antipyretic, antiviral and immunomodulatory potential which revalidates the robust clinical evidences. The scientific analysis of these formulations in this direction with a reverse pharmacological approach will result in a novel drug discovery which is safe and more effective. More over the rapid identification of the exact chemical constituents responsible for therapeutic activity will contribute significantly in selection of unique remedies for emerging and reemerging viral infections in the present arena. The present article throws light on the possible yet undiscovered plant profile, finger printing and probable mechanism of multi-targeted action of single, poly herbal or herbo-mineral formulations exhibited due to its diverse phytochemicals.

\section{Future directions}

A scientific validation of the time-tested clinical evidences of the herbs and formulations documented in classics by a reverse pharmacological approach is the need of the hour.

Phytochemical screening followed by in vitro in vivo studies to prove safety and efficacy.

Incorporation of advanced modern analytical technologies for drug analysis like bioinformatics and other computational technologies to validate the utility of crude drug leads \& their combinations to explore their active constituent, interaction of the drug with human models and elucidate the targeted mechanism of action.

Development of standardized manufacturing principles and analytical techniques to ensure the presence of the active principles of all the raw herbs in the finished product for a better therapeutic outcome.

Repurposing of the formulations in our classics to address diverse disease conditions of varied origins.

Isolation of therapeutically effective crude drug extracts can bring about a newer dimension in the field of medicine.

\section{REFERENCES}

1. Jagetia, Ganesh Chandra, et al. The evaluation of the radioprotective effect of Triphala (an ayurvedic rejuvenating drug) in the mice exposed to $\gamma$ radiation. Phytomedicine 2002; 9.2: 99-108.

2. Agnivesh, Charaka, Charaka Samhita Dridhabala and Jwara Chikitsa Sthana. 3/4, Vaidya Yadavji Trikamji Acharya, editor Reprint ed, Chaukhambha Surbharati Prakashan; 2004. p. 398.

3. Agnivesh, Charaka, Charaka Samhita Dridhabala and Jwara Nidana Sthana. 1/20, Vaidya Yadavji Trikamji Acharya, editor. Chaukhambha Surbharati Prakashan. Reprint ed; 2004. p. 199.

4. Sumanlata, Akanksha S, Rajeev KS, Adnan K. Evaluation of Anti-Inflammatory and Antipyretic Effect of Aqueous Extract of Tinospora cordifolia in Rats; International Journal of Research \& Review 2019; 6(8): 340-346.

5. Yang, Yajun, et al. Chebulagic acid, a hydrolyzable tannin, exhibited antiviral activity in vitro and in vivo against human enterovirus 71. International Journal of Molecular Sciences 2013; 14.5: 9618-9627.

6. Lahon, Joonmoni, Babul Kumar Bezbaruah and Upama Sharma. Analgesic and antipyretic activities of Terminalia 
chebula Retz. fruits extract in experimental animals. International Research Journal of Pharmaceutical and Applied Sciences 2012; 2.6: 159-163.

7. Manoharan, Sivananthan and Jasmin Kaur. Anticancer, antiviral, antidiabetic, antifungal and phytochemical constituents of medicinal plants. Am J PharmTech Res 2013; 3: 149-69.

8. Denyer, Clive V., et al. Isolation of antirhinoviral sesquiterpenes from ginger (Zingiber officinale). Journal of natural products $1994 ; 57.5$ : 658-662.

9. Sahoo, Maheswata, et al. Identification of suitable natural inhibitor against influenza A (H1N1) neuraminidase protein by molecular docking. Genomics \& informatics 2016; 14.3: 96.

10. Ashraf, K. A. M. R. A. N., S. A. D. I. A. Sultan and S. A. A. Shah. Phytochemistry, Phytochemical, Pharmacological and Molecular Study of Zingiber officinale Roscoe: A Review. Int J Pharm Sci 2017; 9.11: 8-16.

11. Gupta, M. B., et al. Pharmacological studies to isolate the active constituents from Cyperus rotundus possessing antiinflammatory, anti-pyretic and analgesic activities. The Indian Journal of Medical Research 1971; 59.1: 76.

12. Zandi, Keivan, et al. Antiviral activity of four types of bioflavonoid against dengue virus type-2. Virology Journal 2011; 8.1: 1-11.

13. $\mathrm{Wu}, \mathrm{Wenjiao}$, et al. Quercetin as an antiviral agent inhibits influenza A virus (IAV) entry. Viruses 2016; 8.1: 6.

14. Gupta, M. B., et al. Anti-inflammatory and antipyretic activities of $\beta$-sitosterol. Planta medica 1980; 39.06: 157 163.

15. Paulpandi, Manickam, et al. In vitro anti-viral effect of $\beta$ santalol against influenza viral replication. Phytomedicine 2012; 19.3-4: 231-235.

16. Qaddir, Iqra, et al. Computer-aided analysis of phytochemicals as potential dengue virus inhibitors based on molecular docking, ADMET and DFT studies. Journal of vector borne diseases 2017; 54.3: 255 .

17. Wu, Wenjiao, et al. Quercetin as an antiviral agent inhibits influenza A virus (IAV) entry. Viruses 2016; 8.1: 6.

18. Louis, L, Jesudoss, Ganthi, Saravana, Padma M, Subramanian, Sorna, Nadu. Comparative Analgesic and Antipyretic activity of ethanolic extract of Tragia plukenetii. Journal of Medical Pharmaceutical and Allied Sciences; 2016. p. 319-326.

19. Hullatti K. K. and M. S. Sharada. Comparative phytochemical investigation of the sources of ayurvedic drug Patha: a chromatographic fingerprinting analysis. Indian Journal of Pharmaceutical Sciences 2010; 72.1: 39 .

20. Hullatti K. K. and M. S. Sharada. Phcog Mag.: Research Article Comparative Antipyretic activity of Patha: An Ayurvedic drug. Phcog Mag 2007; 3.11: 173-76.

21. Wiart, C., et al. Antiviral properties of entlabdene diterpenes of Andrographis paniculata Nees, inhibitors of Herpes simplex virus type 1. Phytotherapy Research: An International Journal Devoted to Pharmacological and Toxicological Evaluation of Natural Product Derivatives 2005; 19.12: 1069-1070.

22. Suebsasana, Supawadee, et al. Analgesic, antipyretic, antiinflammatory and toxic effects of andrographolide derivatives in experimental animals. Archives of Pharmocol research 2009; 32.9: 1191-1200.

23. Anilkumar D, Hemang J, Nishteswa K. Antipyreticanalgesic ayurvedic drugs: an appraisal, Pharma Science Monitor 2012; 3(4): 3032-3046.

24. Trivedi, Anchal, et al. An update on the therapeutic potential of neem and its active constituents: a panacea for all diseases. Era's Journal of Medical Research 2019; 6.1: 110-117.

25. Akram A, Paul S. Antiviral activity of monoterpenes betapinene and limonene against Herpes simplex virus in vitro, Iran J Microbiol 2014; 6(3): 149-155.

26. CN, Shanti Vasudevan, et al. Screening of phytocompounds, molecular docking studies, and in vivo anti-inflammatory activity of heartwood aqueous extract of Pterocarpus santalinus Lf. Asian Pacific Journal of Tropical Biomedicine 2020; 10.

27. Jassim SA, Naji MA. Novel antiviral agents: a medicinal plant perspective. Journal of Applied Microbiology 2003; 95(3): 412-27.

28. Docherty, John J., et al. Resveratrol inhibition of Varicellazoster virus replication in vitro. Antiviral research 2006; 72.3: 171-177.

29. Shekhawat, Neha, and Rekha Vijayvergia. Investigation of anti-inflammatory, analgesic and antipyretic properties of Madhuca indica GMEL. European Journal of Inflammation 2010; 8.3: 165-171.

30. Lalita, Badam. In vitro studies on the effect of glycyrrhizin from Indian Glycyrrhiza glabra Linn on some RNA and DNA viruses. Indian Journal of Pharmacology 1994; 26.3: 194-99.

31. Hoever, Gerold, et al. Antiviral Activity of Glycyrrhizic Acid Derivatives against SARS- Coronavirus. Journal of Medicinal Chemistry 2005; 48.4: 1256-1259.

32. Vijayabaskaran, M., et al. Isolation and Characterization of Phenolic Glycoside from the Bark of Symplocos racemosa Roxb. E-Journal of Chemistry 2012; 7: S255-S260.

33. Lakshman, K., et al. Anti-Inflammatory and Antipyretic activities of Hemidesmus indicus root extract. African Journal of Traditional, Complementary and Alternative Medicines 2006; 3.1: 90-94.

34. Mishra, Nripendra Nath, et al. Herbal gel formulation developed for anti-human immunodeficiency virus (HIV)1 activity also inhibits in vitro HSV-2 infection. Viruses 2018; 10.11: 580.

35. Xiang, Yangfei, et al. In vitro Anti-Herpes Simplex Virus Activity of 1, 2, 4, 6-Tetra-O-galloyl- $\beta$-d-glucose from Phyllanthus embelica L. (Euphorbiaceae). Phytotherapy Research 2011; 25.7: 975-982.

36. Mukherjee, P. K., et al. Antipyretic activity of Nelumbo nucifera rhizome extract. Indian Journal of Experimental Biology 1996; 34.3: 275-76.

37. Kuo, Yuh-Chi, et al. Herpes simplex virus type 1 propagation in HeLa cells interrupted by Nelumbo nucifera. Journal of Biomedical Science 2005; 12.6: 10211034.

38. Pandurangan, Subash-Babu, et al. Antinociceptive, immunomodulatory and antipyretic activity of nymphayol isolated from Nymphaea stellata (Wild) flowers. Biomolecules \& therapeutics 2013; 21.5: 391.

39. Das, Debajyoti, et al. Evaluation of antipyretic and analgesic activity of Parusaka (Grewia asiatica Linn.): an indigenous Indian plant. International Journal of Research in Ayurveda and Pharmacy (IJRAP) 2012; 3.4: 519-523.

40. Liu, Ai-Lin, and Guan-Hua Du. Antiviral properties of phytochemicals. Dietary phytochemicals and microbes. Springer, Dordrecht; 2012. p. 93-126.

41. Maity, Pallab, et al. Biological activities of crude extracts and chemical constituents of Bael, Aegle marmelos (L.) Corr; 2009. p. 849-861.

42. Aiken, Christopher and Chin Ho Chen. Betulinic acid derivatives as HIV-1 antivirals. Trends in molecular medicine 2005 ; 11.1: 31-36. 
43. Pavlova, N. I., et al. Antiviral activity of betulin, betulinic and betulonic acids against some enveloped and nonenveloped viruses. Fitoterapia 2003; 74.5: 489-492.

44. Dawane, Jayshree Shriram, Vijaya Pandit, and Kanchan Borole. Experimental evaluation of antipyretic activity of aqueous extract of Dashamula. Spatula DD 2012; 2.1: 1721.

45. Hussain, Hidayat, et al. Lapachol: an overview. Arkivoc 2007; 2.1: 145-171.

46. Funakoshi-Tago, Megumi, et al. Anti-inflammatory activity of structurally related flavonoids, Apigenin, Luteolin and Fisetin. International immunopharmacology 2011; 11.9: 1150-1159.

47. Pardeshi, Jaywant, et al. Physico-chemical and preliminary phytochemical screening of roots of some species of Dashamula. Journal of Pharmacognosy and Phytochemistry 2018; 7.3: 2690-2693.

48. Nag, Mrinmoy, et al. Evaluation of antimicrobial potential of some Indian ayurvedic medicinal plants. Pharmacognosy Journal 2016; 8.6: 525-533.

49. Khandaker, Mahia, Saleha Akter and Mohammad Zafar Imam. Trichosanthes dioica Roxb.: A vegetable with diverse pharmacological properties. Food Science and Human Wellness 2018; 7.1: 34-48.

50. Ghildiyal, Ritu, et al. Phytochemicals as Antiviral Agents: Recent Updates. Plant-derived Bio-actives. Springer, Singapore; 2020. p. 279-295.

51. Perianayagam, James B., et al. Evaluation of anti-pyretic and analgesic activity of Emblica officinalis Gaertn. Journal of ethnopharmacology 2004; 95.1: 83-85.

52. Pria, Firuz Fatema, and Mohammad Sayful Islam. Phyllanthus emblica Linn. (Amla)-A Natural Gift to Humans: An Overview. Journal of Diseases and Medicinal Plants 2019; 5.1: 1-9.

53. Win, Nwet Nwet, et al. Bis-iridoid and iridoid glycosides: viral protein R inhibitors from Picrorhiza kurroa collected in Myanmar. Fitoterapia 2019; 134: 101-107.

54. Xu, Weiming, et al. Antiviral activity of aconite alkaloids from Aconitum carmichaelii Debx. Natural product research 2019; 33.10: 1486-1490.

55. Sabina, Evan Prince, et al. Analgesic, antipyretic and ulcerogenic effects of Piperine: an active ingredient of pepper. Journal of Pharmaceutical Sciences and Research 2013; 5.10: 203.

56. Mair, C. E., et al. Antiviral and anti-proliferative in vitro activities of piperamides from black pepper. Planta Medica 2016; 82.S 01: P807.

57. Ghoke, S. S., et al. Evaluation of antiviral activity of Ocimum sanctum and Acacia arabica leaves extracts against H9N2 virus using embryonated chicken egg model. BMC complementary and alternative medicine 2018; 18.1: 174.

58. Yamazaki Z, Tagaya I. Antiviral effects of atropine and caffeine. J Gen Virol 1980; 50: 429-31.

59. Weld, Julia T., and Anne Gunther. The antibacterial properties of sulfur. The Journal of Experimental Medicine 1947; 85.5: 531-542.

60. Jaganathan M. Scientific validation of siddha herbomineral formulation Linga Mathirai. World Journal of Pharmaceutical Research 2019; 8: 746-757.

61. Sarkar, Prasanta Kumar, et al. Evaluation of processed borax as antidote for aconite poisoning. Journal of ethnopharmacology 2017; 205: 138-146.

62. Gonçalves, J. L. S., et al. In vitro anti-rotavirus activity of some medicinal plants used in Brazil against diarrhea. Journal of ethnopharmacology 2005; 99.3: 403407.
63. Bellavite, Paolo, and Alberto Donzelli. Hesperidin and SARS-CoV-2: new light on the healthy function of citrus fruits. Antioxidants 2020; 9.8: 742.

64. Srinivasan, K., et al. Antinociceptive and antipyretic activities of Pongamia pinnata leaves. Phytotherapy Research 2003; 17.3: 259-264.

65. Elanchezhiyan, M., et al. Antiviral properties of the seed extract of an Indian medicinal plant, Pongamia pinnata, Linn., against Herpes simplex viruses: in-vitro studies on Vero cells. Journal of medical microbiology 1993; 38.4: 262-264.

66. Wen, Chih-Chun, et al. Traditional Chinese medicine herbal extracts of Cibotium barometz, Gentiana scabra, Dioscorea batatas, Cassia tora, and Taxillus chinensis inhibit SARS-CoV replication. Journal of traditional and complementary medicine $2011 ; 1.1$ : 41-50.

67. Niranjan, Abhishek, and Dhan Prakash. Chemical constituents and biological activities of turmeric (Curcuma longa L.)-a review. Journal of Food Science and Technology 2008; 45.2: 109.

68. Semwal, Ruchi Badoni, et al. Spectral studies and pharmacological relevance of berberine isolated from Berberis aristata roots. Current Medical and Drug Research 2018; 2 (1): 1-8.

69. Mukherjee, Pulok Kumar, et al. Acorus calamus.: Scientific validation of Ayurvedic tradition from natural resources. Pharmaceutical biology 2007; 45.8: 651-666.

70. Al-Snafi, Ali Esmail. Therapeutic properties of medicinal plants: a review of their immunological effects (part 1). Asian Journal of Pharmaceutical Research 2015; 5.3: 208-216.

71. Bhattacharya, Ayon, et al. Antipyretic effect of ethanolic extract of Moringa oleifera leaves on albino rats. Tanta Medical Journal 2014; 42.2: 74.

72. Vasundra, D. P. A., and P. S. Divya. Antipyretic activity of ethanol and aqueous extract of root of Asparagus racemosus in yeast induced pyrexia. Asian Journal of Pharmaceutical and clinical research 2013; 6.3: 190-193.

73. Ovadia, Michael. Antiviral preparations obtained from a natural cinnamon extract. U.S. Patent No. 9,364,511. 14 Jun; 2016.

74. Waheed, Yasir, Sher Zaman Safi, and Ishtiaq Qadri. Role of Potash Alum in hepatitis C virus transmission at barber's shop. Virology journal 2011; 8.1: 211.

75. Brown, C. L., et al. Gold 2006 presentation nanogold pharmaceutics. Gold Bull 2007; 40.3: 245-250.

76. Di Gianvincenzo, Paolo, et al. Gold nanoparticles capped with sulfate-ended ligands as anti-HIV agents. Bioorganic \& medicinal chemistry letters 2010; 20.9: 2718-21.

77. Sultan, S., et al. Antipyretic activity of hydro-methanolic extract of Trachyspermum ammi Linn. seeds in rabbits. Pakistan Journal of Science 2018; 70.2: 109.

78. Alburn, Harvey E., and George Greenspan. Thymol as an anti-influenza agent. U.S. Patent No. 3,632,782. 4 Jan; 1972.

79. Yadav, Pradeep Kumar, Amit Jaiswal, and Rajiv Kumar Singh. In Silico Study on Spice-Derived Antiviral Phytochemicals Against SARS-CoV-2 TMPRSS2 Target; 2020.

80. Bauer, D. J. The chemotherapeutic activity of compounds of copper, rhodium and certain other metals in mice infected with neurovaccinia and ectromelia viruses. British Journal of Experimental Pathology 1958; 39.5: 480.

81. Wang, Dan, et al. Comparison of antiviral activity of realgar and nano-realgar against Herpes simplex virus type II (HSV-2) in vitro; 2019. 
82. Surjushe, Amar, Resham Vasani, and D. G. Saple. Aloe vera: a short review. Indian Journal of Dermatology 2008; 53.4: 163

83. Kothar, Saroj. Paracetamol like antipyretic activity of lyophilized succulent of Aloe vera leaves in rats. International Journal of Green Pharmacy (IJGP) 2015; 9.4.

84. Mukherjee, Pulok Kumar, et al. Acorus calamus.: Scientific validation of Ayurvedic tradition from natural resources. Pharmaceutical biology 2007; 45.8: 651-666.

85. Jeyadevi, R., et al. Chemical constituents and antimicrobial activity of Indian green leafy vegetable Cardiospermum halicacabum. Indian Journal of Microbiology 2013; 53.2: 208-213.

86. Habte, Habtom H., et al. Antiviral activity of purified human breast milk mucin. Neonatology 2007; 92.2: 96104.

87. Wink, Michael. Modes of action of herbal medicines and plant secondary metabolites. Medicines 2015; 2.3: 251286.

88. Mackowiak PA. Concepts of fever. Archives of Internal Medicine 1998; 28, 158(17): 1870-81.

89. Grundmann, M. Studies on the action of antipyretic substances. Diss. University of Oxford; 1969.

90. Hämäläinen, Mari, et al. Anti-inflammatory effects of flavonoids: genistein, kaempferol, quercetin, and daidzein inhibit STAT-1 and NF- $\mathrm{BB}$ activations, whereas flavone, isorhamnetin, naringenin and pelargonidin inhibit only NF$\kappa \mathrm{B}$ activation along with their inhibitory effect on iNOS expression and NO production in activated macrophages. Mediators of inflammation; 2007.

91. Gupta, Mradu, B. P. Shaw, and A. Mukherjee. A new glycosidic flavonoid from Jwarahara Mahakashaya (antipyretic) Ayurvedic preparation. International Journal of Ayurveda research 2010; 1.2: 106.

92. Baumann, J., F. V. Bruchhausen, and G. Wurm. Flavonoids and related compounds as inhibitors of arachidonic acid peroxidation. Prostaglandins 1980; 20.4: 627-639.

93. Ramàkrishnamacharya $\mathrm{CH}$, Vanitha Muralikumar, and Chandrasekar Seshachalam. Inhibitory Effect of Phytochemicals from Azadirachta indica A Juss. and Tinospora cordifolia (Thunb.) Miers against SARS-CoV-2 $\mathrm{M}$ pro and Spike Protease-An in-silico Analysis. Science Open Preprints; 2020.

94. Hoever, Gerold, et al. Antiviral Activity of Glycyrrhizic Acid Derivatives against SARS- Coronavirus. Journal of medicinal chemistry 2005 ; 48.4: 1256-1259.

95. Wu, Wenjiao, et al. Quercetin as an antiviral agent inhibits influenza A virus (IAV) entry. Viruses 2016; 8.1: 6.

96. Baba, Masanori, and Shiro Shigeta. Antiviral activity of glycyrrhizin against varicella-zoster virus in vitro. Antiviral research 1987; 7.2: 99-107.

97. Kurokawa, Masahiko, et al. Efficacy of traditional herbal medicines in combination with acyclovir against Herpes simplex virus type 1 infection in vitro and in vivo. Antiviral research 1995; 27.1-2: 19-37.

98. Mathew, Dony, and Wei-Li Hsu. Antiviral potential of curcumin. Journal of functional foods 2018; 40: 692-699.
99. Mukherjee, Pulok Kumar, et al. Acorus calamus.: Scientific validation of Ayurvedic tradition from natural resources. Pharmaceutical biology 2007; 45.8: 651-666.

100. Lai, Wen-Lin, et al. Inhibition of Herpes simplex virus type 1 by thymol-related monoterpenoids. Planta medica 2012; 78.15: 1636-1638.

101. Astani, Akram, Jürgen Reichling, and Paul Schnitzler. Screening for antiviral activities of isolated compounds from essential oils. Evidence-based complementary and alternative medicine; 2011.

102. Cinatl, J., et al. Glycyrrhizin, an active component of liquorice roots, and replication of SARS-associated coronavirus. The Lancet 2003; 361.9374: 2045-2046.

103. Zandi, Keivan, et al. Evaluation of antiviral activities of curcumin derivatives against HSV-1 in Vero cell line. Natural product communications 2010; 5.12: $1934578 X 1000501220$.

104. Alarcón, Balbino, Maria Eugenia González, and Luis Carrasco. Anti-herpes virus action of atropine. Antimicrobial agents and chemotherapy 1984; 26.5: 702706.

105. Badam, Lalita, S. P. Joshi, and S. S. Bedekar. In vitro' antiviral activity of neem (Azadirachta indica. A. Juss) leaf extract against group B coxsackieviruses. The Journal of communicable diseases 1999; 31.2: 79-90.

106. Hussain, Liaqat, et al. The analgesic, anti-inflammatory and anti-pyretic activities of Tinospora cordifolia. Advances in Clinical and Experimental Medicine 2015; 24.6: 957-964.

107. Lahon, Joonmoni, Babul Kumar Bezbaruah, and Upama Sharma. Analgesic and antipyretic activities of Terminalia chebula Retz. fruits extract in experimental animals. International Research Journal of Pharmaceutical and Applied Sciences 2012; 2.6: 159-163.

108. Bharathi, C., et al. A Review on Medicinal Properties of Tinospora cordifolia. International Journal of Scientific Research and Review 2018; 7: 585-598.

109. Lin, Liang-Tzung, et al. Hydrolyzable tannins (chebulagic acid and punicalagin) target viral glycoproteinglycosaminoglycan interactions to inhibit Herpes simplex virus 1 entry and cell-to-cell spread. Journal of virology 2011; 85.9: 4386-4398.

110. Chakotiya, Ankita Singh, and Rakesh Kumar Sharma. Phytoconstituents of Zingiber officinale Targeting Hostviral Protein Interaction at Entry Point of SARS-CoV-2: A Molecular Docking Study.

111. Nair, PK Raveendran, et al. Mechanism of macrophage activation by $(1,4)-\alpha$-D-glucan isolated from Tinospora cordifolia. International Immunopharmacology 2006; 6.12: 1815-1824.

112. Gupta, Mradu, B. P. Shaw, and A. Mukherjee. A new glycosidic flavonoid from Jwarahara Mahakashaya (antipyretic) Ayurvedic preparation. International Journal of Ayurveda research 2010; 1.2: 106.

\section{Cite this article as:}

Hareendran Nair J et al. A critical review of Jwarahara Yogas of Ayurvedic Classics: A Paradigm to Reverse Pharmacology. Int. J. Res. Ayurveda Pharm. 2021;12(1):85-95 http://dx.doi.org/ $\underline{10.7897 / 2277-4343.120120}$

Disclaimer: IJRAP is solely owned by Moksha Publishing House - A non-profit publishing house, dedicated to publishing quality research, while every effort has been taken to verify the accuracy of the content published in our Journal. IJRAP cannot accept any responsibility or liability for the site content and articles published. The views expressed in articles by our contributing authors are not necessarily those of IJRAP editor or editorial board members. 